$\xi=-1$

\title{
Solving non-convex economic dispatch with prohibited zones using artificial fish swarm optimization
}

\author{
Ko Jun Seog ${ }^{1}$, S. Surender Reddy ${ }^{2}$, Chan-Mook Jung ${ }^{3}$ \\ ${ }^{1}$ Korea Rail Network Authority, Daejeon, Republic of Korea \\ ${ }^{2}$ Department of Railroad and Electrical Engineering, Woosong University, Daejeon, Republic of Korea \\ 3 Department of Railroad and Civil Engineering, Woosong University, Daejeon, Republic of Korea \\ *Corresponding author E-mail: salkuti.surenderreddy@gmail.com
}

\begin{abstract}
In this paper, a novel approach is proposed to solve the non-convex and discontinuous economic dispatch (ED) problem of power system with thermal power plants. All the practical constraints (loss constraint, generators ramp rate constraints and network constraints) are considered for solving the ED problem. Here, the proposed ED problem is solved by considering the generators with valve point loading (VPL) effects and prohibited operating zones (POZs) effects. In this paper, to solve this practical ED problem, an evolutionary based Artificial Fish Swarm Optimization Algorithm (AFSOA) is utilized. The AFSOA is a global search algorithm based on the characteristics of fish swarm and its autonomous model. The detailed algorithm with its flow chart is presented in this paper. To show the effectiveness of the proposed ED approach, 3 test systems (3, 6 and 20 generating unit systems) are considered. The obtained results are compared with other algorithms reported in the literature.
\end{abstract}

Keywords: Economic Dispatch; Fuel Cost; Network Constraints; Valve Point Loading; Prohibited Zones; Evolutionary Algorithm.

\section{Nomenclature}

$a_{i}, b_{i}, c_{i}$ Fuel cost coefficients of thermal generators.

$\mathrm{F}_{\mathrm{T}}$ Total cost/operating cost of generation $(\$ / \mathrm{hr})$.

$\mathrm{N}_{\mathrm{G}}$ Total number of generators.

$\mathrm{P}_{\mathrm{Gi}}$ Active power generation from $\mathrm{i}^{\text {th }}$ thermal generator.

$\mathrm{C}_{\mathrm{i}}$ Fuel cost function of $\mathrm{i}^{\text {th }}$ thermal generator.

$d_{i}, e_{i}$ Factors for the valve point loading (VPL) effects on $i^{\text {th }}$ generator.

$\mathrm{P}_{\mathrm{Gi}, \mathrm{j}}^{\mathrm{l}}, \mathrm{P}_{\mathrm{Gi}, \mathrm{j}}^{\mathrm{u}}$ Lower and upper limits of $\mathrm{j}^{\text {th }}$ prohibited zone for $\mathrm{i}^{\text {th }}$ generator.

$\mathrm{z}_{\mathrm{i}}$ Number of prohibited operating zones (POZs) of $\mathrm{i}^{\text {th }}$ generator.

$\mathrm{P}_{\mathrm{Gi}}^{\min }, \mathrm{P}_{\mathrm{Gi}}^{\max }$ Minimum and maximum limits of power output from $\mathrm{i}^{\text {th }}$ generator.

$\mathrm{P}_{\mathrm{D}}$ Total power demand in the system.

$\mathrm{P}_{\text {loss }}$ Transmission losses in the system.

$\mathrm{B}_{\mathrm{ij}}, \mathrm{B}_{\mathrm{i} 0}, \mathrm{~B}_{00}$ Transmission loss coefficients/ B coefficients.

$\mathrm{P}_{\mathrm{Gi}}^{0}$ Power output from $\mathrm{i}^{\text {th }}$ generator in previous hour.

$\mathrm{R}_{\mathrm{i}}^{\text {down }}, \mathrm{R}_{\mathrm{i}}^{\text {up }}$ Ramp down and ramp up limits of $\mathrm{i}^{\text {th }}$ generator.

$\mathrm{S}_{\mathrm{Li}}$ Power flow through $\mathrm{i}^{\text {th }}$ transmission line.

$\mathrm{S}_{\mathrm{Li}}^{\max }$ Thermal/maximum power flow limit of $\mathrm{i}^{\text {th }}$ trans- mission line.

step Step range/ maximum step size of an artificial fish.

$\delta$ Congestion factor of artificial fish.

$\mathrm{X}_{\mathrm{i}}$ Position within the scope of the vision of the fish.

$\mathrm{X}^{\text {opt }}$ Optimal position.

$\mathrm{n}_{\mathrm{f}}$ Number of artificial fish.

$\mathrm{X}_{\mathrm{c}}$ Center of the swarm.

$\mathrm{d}_{\text {visual }}$ Perceiving range of an artificial fish.

\section{Introduction}

The use of electricity is indispensable and the demand for electricity is increasing day-by-day. The quality of electricity is stated in terms of constant voltage, frequency and uninterrupted power supply at minimum cost. The quantity of coal and the cost of coal used in the generation of power in a thermal plant is directly dependant on the power output produced. Hence, to deliver the power at minimum cost, there is a requirement to reduce the amount of fuel used. This simple solution for this is the use of more efficient generating units. But, there is a certain maximum limit for the efficiency of the generating units. Therefore, for a particular power output, the operating schedule with the distribution of load demand among various generating units, which results in optimum generating cost is required. Obtaining such appropriate schedule is the economic dispatch (ED) problem. The purpose of the traditional ED problem is to find the most economical schedule of the generating units while satisfying load demand and operational constraints. This involves the allocation of active power between the generating units, as the operating cost is insensitive to the reactive loading of a generator [1].

In the literature, there are several methods proposed for solving the ED problem. A distributed consensus-based approach to solve the ED problem with generator constraints and transmission losses is proposed in [2]. Reference [3] presents a review on inaccuracy issues related to solve the practical formulation of the ED problem. Reference [4] presents cuckoo search algorithm for solving both convex and non-convex ED problems of fossil fuel fired generators considering transmission losses, multiple fuels, valvepoint loading (VPL) and prohibited operating zones (POZs) effects. An exchange market algorithm for solving ED problem is 
proposed in [5]. An algorithm inspired on the T-Cell model of the immune system is proposed in [6] to solve the ED problem. Combined economic/environmental dispatch treats the economic and environmental impact as competing objectives and this problem is solved in [7]. An improved differential evolution (DE) to the solve ED problem of thermal generating units with non-smooth/nonconvex cost functions due to VPL, taking into account the transmission losses and non-linear generator constraints such as POZs is proposed in [8]. Reference [9] applies a number of PSO variants to the dynamic economic emission dispatch (DEED) problem. Reference [10] proposes a modified version of social spider algorithm and its application to solve the non-convex ED problem. Chaotic bat algorithm is proposed in [11] and hybrid grey wolf optimizer is proposed in [12] are used to solve the non-linear and discontinuous ED problem.

A diffusion particle optimization algorithm is proposed in [13] for solving a dispatch model that considers fuel, emissions control and wind power cost. A self-adoptive learning with time varying acceleration coefficient-gravitational search algorithm is proposed in [14] to solve a highly nonlinear, non-convex, non-smooth, nondifferential, and high-dimension ED problem. Reference [15] proposes a combined model of multi-objective dynamic economic and emission dispatch problem. An orthogonal learning competitive swarm optimizer is proposed in [16] for solving the ED problem. Reference [17] presents a comprehensive review on the uses of different optimization techniques to solve the combined economic and emission dispatch problem.

The aim of this paper is to investigate the applicability of Artificial Fish Swarm Optimization Algorithm (AFSOA) for solving the conventional and practical ED problem with non-convex discontinuous objective function. The AFSOA is tested on three standard test systems that are extremely difficult or impossible to solve by using the standard techniques due to the non-continuous, nonconvex and highly nonlinear solution space of the problem.

The remainder of this paper is organized as follows. Section 2 presents the problem formulation of conventional and practical economic dispatch (ED) problem. The description of Artificial fish swarm optimization algorithm (AFSOA) is presented in Section 3. Simulation results and discussions are presented in Section 4. Finally, Section 5 presents the contributions with concluding remarks.

\section{Economic dispatch (ED): problem formula- tion}

The objective of ED problem is to determine the optimal combination of power outputs of all the generating units to minimize the total fuel cost while satisfying several equality and inequality constraints. Hence, the ED problem is a constrained optimization problem and it can be expressed as [18],

Minimize,

$\mathrm{F}_{\mathrm{T}}=\sum_{\mathrm{i}=1}^{\mathrm{N}_{\mathrm{G}}} \mathrm{C}_{\mathrm{i}}\left(\mathrm{P}_{\mathrm{Gi}}\right)$

Subject to a number of power systems network equality and inequality constraints.

Each generator cost function $\left(\mathrm{C}_{\mathrm{i}}\left(\mathrm{P}_{\mathrm{Gi}}\right)\right)$ establishes the relationship between the power injected to the system by the generator and the incurred costs to load the machine to that capacity. Generally, the fuel cost function is considered as a smooth quadratic functions and it is depicted in Figure 1.

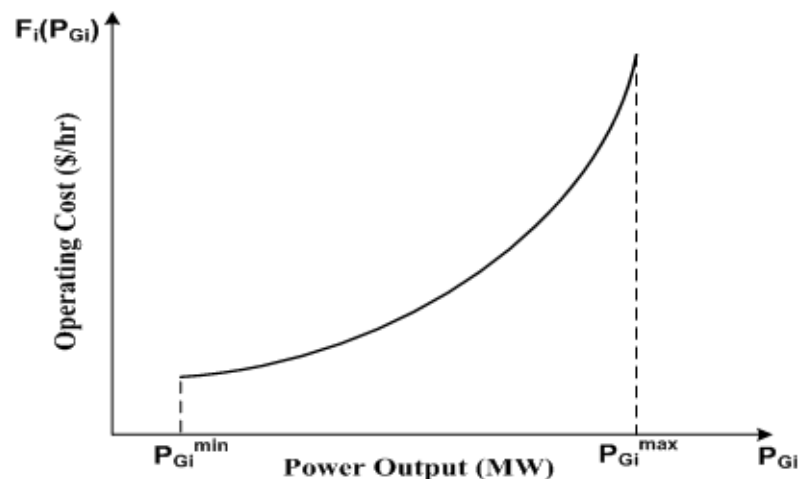

Fig. 1: Smooth Quadratic Fuel Cost Curve of Thermal Generator.

Mathematically, the Smooth Quadratic Cost Function of A Generating Unit Can Be Expressed As [19],

$\mathrm{F}_{\mathrm{T}}=\sum_{\mathrm{i}=1}^{\mathrm{N}_{\mathrm{G}}} \mathrm{C}_{\mathrm{i}}\left(\mathrm{P}_{\mathrm{Gi}}\right)=\sum_{\mathrm{i}=1}^{\mathrm{N}_{\mathrm{G}}}\left(\mathrm{a}_{\mathrm{i}}+\mathrm{b}_{\mathrm{i}} \mathrm{P}_{\mathrm{Gi}}+\mathrm{c}_{\mathrm{i}} \mathrm{P}_{\mathrm{Gi}}^{2}\right)$

\subsection{ED considering valve point loading (VPL) effects}

In steam power plants, several steam valves are used in turbine for controlling the power output of generators. Opening the valvepoint effects would lead to a sudden increase in loss and causes ripples in input-output curve and consequently causes cost function non-smooth. The generator cost function is obtained from a data point taken during the heat run tests when input and output data are measured as the unit slowly varies through its operating region [20]. The VPL effect of a generator is depicted in Figure 2.

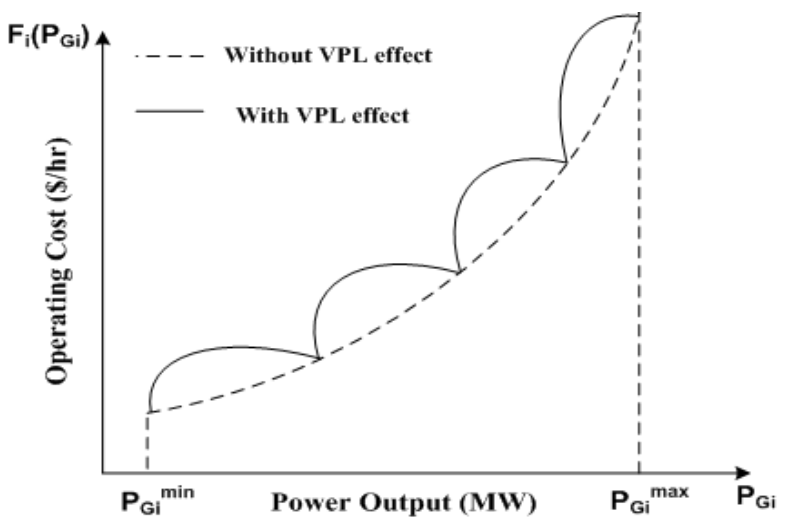

Fig. 2: Fuel Cost Curve of Generators with VPL Effects (with 4 Steam Valves).

Mathematically, the VPL effect is expressed as [21],

$\mathrm{F}_{\mathrm{T}}=\sum_{\mathrm{i}=1}^{\mathrm{N}_{\mathrm{G}}} \mathrm{C}_{\mathrm{i}}\left(\mathrm{P}_{\mathrm{Gi}}\right)=\sum_{\mathrm{i}=1}^{\mathrm{N}_{\mathrm{G}}}\left[\mathrm{a}_{\mathrm{i}}+\mathrm{b}_{\mathrm{i}} \mathrm{P}_{\mathrm{Gi}}+\mathrm{c}_{\mathrm{i}} \mathrm{P}_{\mathrm{Gi}}^{2}+\mid \mathrm{d}_{\mathrm{i}} \times\right.$ $\left.\sin \left\{\mathrm{e}_{\mathrm{i}} \times\left(\mathrm{P}_{\mathrm{Gi}}^{\min }-\mathrm{P}_{\mathrm{Gi}}\right)\right\} \mid\right]$

\subsection{ED considering prohibited operating zones (POZs) effects}

The POZs are the range of power output of a generator where the operation causes undue vibration of the turbine shaft bearing caused by closing or opening of the steam valve, and makes the cost curve discontinuous in nature. This might cause damage to the shaft and bearings. Therefore, in order to achieve best economy, the operation of generators in such regions is avoided [22]. The POZs effect of generators is depicted in Figure 3. 


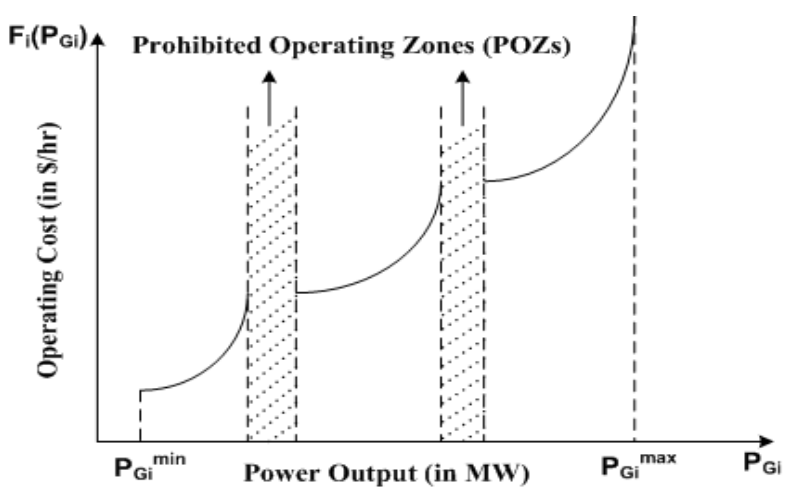

Fig. 3: Fuel Cost Curve of Generators with POZs Effects.

Mathematically, the POZs constraints are represented by,

$$
P_{G i} \in\left\{\begin{array}{l}
P_{G i}^{\min } \leq P_{G i} \leq P_{G i}^{l} \\
P_{G i, j-1}^{u} \leq P_{G i} \leq P_{G i, j}^{l} j=2,3 \ldots, z_{i} \\
P_{G i, z_{i}}^{u} \leq P_{G i} \leq P_{G i}^{\max }
\end{array}\right.
$$

\subsection{Equality and inequality constraints}

\subsubsection{Equality constraint}

The power balance/equality constraint reduces the system to a basic principle of equilibrium between total system generation and total system loads. According to this, the total generation must be equal to the total system demand plus the transmission losses in the system, and it is expressed as,

$\sum_{\mathrm{i}=1}^{\mathrm{N}_{\mathrm{G}}} \mathrm{P}_{\mathrm{Gi}}=\mathrm{P}_{\mathrm{D}}+\mathrm{P}_{\text {loss }}$

To calculate $\mathrm{P}_{\text {loss }}$, B coefficients method is used in this paper, and it is formulated by,

$\mathrm{P}_{\text {loss }}=\sum_{\mathrm{i}=1}^{\mathrm{N}_{\mathrm{G}}} \sum_{\mathrm{i}=1}^{\mathrm{N}_{\mathrm{G}}} \mathrm{P}_{\mathrm{i}} \mathrm{B}_{\mathrm{ij}} \mathrm{P}_{\mathrm{j}}+\sum_{\mathrm{i}=1}^{\mathrm{N}_{\mathrm{G}}} \mathrm{P}_{\mathrm{Gi}} \mathrm{B}_{\mathrm{i} 0}+\mathrm{B}_{00}$

\subsubsection{Inequality constraints}

a) Power Generation Constraint:

The operating region of generator is restricted by,

$\mathrm{P}_{\mathrm{Gi}}^{\min } \leq \mathrm{P}_{\mathrm{Gi}} \leq \mathrm{P}_{\mathrm{Gi}}^{\max }$

b) Ramp Rate Constraints:

Generally, the power output from the generator is assumed to be adjusted instantaneously. But, in practice, the ramp rate limits restrict the operating region of generator. Therefore, by including the ramp rate limits, the equation (7) becomes,

$\max \left(\mathrm{P}_{\mathrm{Gi}}^{\min }, \mathrm{P}_{\mathrm{Gi}}^{0}-\mathrm{R}_{\mathrm{i}}^{\text {down }}\right) \leq \mathrm{P}_{\mathrm{Gi}} \leq \max \left(\mathrm{P}_{\mathrm{Gi}}^{\max }, \mathrm{P}_{\mathrm{Gi}}^{0}+\mathrm{R}_{\mathrm{i}}^{\mathrm{up}}\right)$

c) Network/Power Flow Constraint:

The power flow through the transmission line is limited by the thermal capability of the circuit and it is expressed as,

$\mathrm{S}_{\mathrm{Li}} \leq \mathrm{S}_{\mathrm{Li}}^{\max }$

The presented objective function with constraints is solved by using the Artificial Fish Swarm Optimization Algorithm (AFSOA), and the description of AFSOA is presented next:

\section{Artificial fish swarm optimization algo- rithm (AFSOA)}

The AFSOA is a meta-heuristic algorithm, which is a comparatively topical accumulation to the pasture of natural computing, that has rudiments enthused by the societal behaviors of natural swarms, and associates with evolutionary computation. It has an extensive application in multifaceted optimization domains, and currently a foremost research focus, contribution an unconventional to the more established meta-heuristic techniques that may applied in many of the identical domains [23].

AFSOA has several characteristics that are similar to genetic algorithm (GA) such as sovereignty from incline in sequence of purpose occupation, the capability to resolve multifaceted nonlinear high dimensional exertion [23]. Furthermore, they canister accomplish closer convergence swiftness and entail the minority parameters to bend. Whereas, the AFSOA does not seize the crossover and mutation processes utilize in GA, so it could achieve more simply.

In nature, the fish can find out the more nutritious area by individual search or following other fish, the area with much more fish is commonly most nutritious. The fundamental idea of the AFSOA is to reproduce the fish behaviors such as praying, swarming, and following with local search of fish individual for attaining the global optimum. Fish habitually reside within the place having a lot of food. Therefore, the behaviors of fish is imitated based on this attribute to come across the global optimum, which is the indispensable inspiration of the AFSOA. In this paper, the artificial fish denotes the decision variables used in the optimization problem. The power output from each generating unit forms the artificial fishes. Various steps that are involved for the implementation of AFSOA is described next.

\subsection{Initialization}

The position of each artificial fish denotes a possible potential solution. They are the decision variables used in the optimization problem. The current position $\left(\mathrm{X}_{\mathrm{i}}\right)$ can be represented as [24],

$\mathrm{X}_{\mathrm{i}}=\left(\mathrm{X}_{\mathrm{i} 1}, \mathrm{X}_{\mathrm{i} 2}, \mathrm{X}_{\mathrm{i} 3}, \ldots \ldots, \mathrm{X}_{\mathrm{in}}\right)$

Where $\mathrm{i}$ is number control variables, $\mathrm{X}_{\mathrm{i}}$ denotes an initial solution, $\mathrm{n}$ is number fishes in the swarm (i.e., swarm length).

\subsection{Fitness function evaluation}

The fitness function (FF) is formulated as a function of current position $\left(\mathrm{X}_{\mathrm{i}}\right)$ and it is expressed as,

$\mathrm{FF}_{\mathrm{i}}=\mathrm{f}\left(\mathrm{X}_{\mathrm{i}}\right)$

The position is defined by different behaviors of fish and they are described as follows:

\subsection{Preying behaviour}

This fundamental biological behavior tends to the food. Let the condition of artificial fish is $X_{i}$, choosing a state $X_{j}$ inside its sensing range arbitrarily. Suppose $X_{j}$ is superior to $X_{i}$, then move to $X_{j}$, otherwise to the selected arbitrarily condition $X_{i}$. Determine whether to meet the forward conditions, repeated several times, if still not satisfied forward conditions, then move one step randomly. The food concentration in this position of fish is stated as the objective function value. The distance between the artificial fish is [25-26] expressed as,

$\mathrm{d}_{\mathrm{ij}}=\left\|\mathrm{X}_{\mathrm{i}}-\mathrm{X}_{\mathrm{j}}\right\|$

$\mathrm{X}_{\mathrm{j}}=\mathrm{X}_{\mathrm{i}}+\left(\mathrm{d}_{\mathrm{visual}} \cdot \operatorname{rand}()\right)$ 
Where $d_{\text {visual }}$ is the distance through which the artificial fish can see (i.e., perceiving range/visual distance) [27], and rand () produces random numbers between 0 and 1 .

$X_{i}^{(t+1)}=X_{i}^{t}+\left(\frac{X_{j}-X_{i}^{t}}{\left\|X_{i}-X_{i}^{t}\right\|} \cdot\right.$ step. $\operatorname{rand}(O)$

Where step is the maximum distance that a fish can move in one movement.

\subsection{Swarming behaviour}

Let the current position of artificial fish is $\mathrm{X}_{\mathrm{i}}$ and $\left(\mathrm{d}_{\mathrm{ij}}<\mathrm{d}_{\mathrm{visual}}\right)$. Then, $\left(\mathrm{n}_{\mathrm{f}}<\delta\right)$ indicates that the partners have more food and less crowded. Artificial fish has a tendency to move towards the center of the swarm, to ensure the presence of swarm around it and to avoid any potential danger. Now, the updated position is given by [28],

$\mathrm{X}_{\mathrm{i}}^{(\mathrm{t}+1)}=\mathrm{X}_{\mathrm{i}}^{\mathrm{t}}+\left(\frac{\mathrm{X}_{\mathrm{c}}-\mathrm{X}_{\mathrm{i}}^{\mathrm{t}}}{\left\|\mathrm{X}_{\mathrm{c}}-\mathrm{X}_{\mathrm{i}}^{\mathrm{t}}\right\|}\right.$. step. rand $)$

\subsection{Following behaviour}

Let the state of artificial fish is $\mathrm{X}_{\mathrm{i}}$ exploring its optimal state $\mathrm{X}^{\mathrm{opt}}$ from the visual neighbors. Suppose, the number of partners of $\mathrm{X}^{\mathrm{opt}}$ is $\left(\mathrm{n}_{\mathrm{f}}<\delta\right)$ indicates that near distance have more food, not too crowed and can move further. Otherwise, perform the prey behavior by using the equation (13) [28].

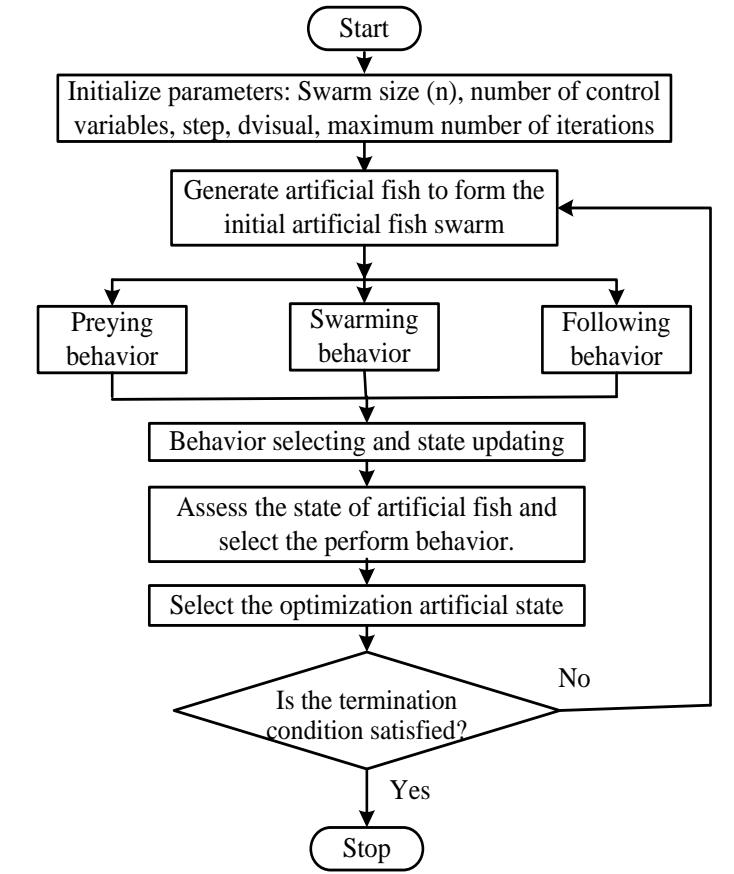

Fig. 4: Flow Chart of Artificial Fish Swarm Optimization Algorithm (AFSOA).

\section{Results and discussion}

To show the effectiveness of the proposed ED approach, 3 test systems, i.e., 3, 6 and 20 generating unit systems are considered in this paper. Here, the AFSO algorithm is used to solve the proposed non-convex and discontinuous ED problem. The parameters considered in this paper are: Population size is 60, step is 1 and the maximum number of iterations are 200 .

\subsection{Simulation results on 6 bus - 3 generator system}

The data required for performing the ED problem is taken from [29]. Here, the ED is performed by considering 3 power demands, i.e., $\mathrm{P}_{\mathrm{D}}$ are $300 \mathrm{MW}, 850 \mathrm{MW}$ and $1150 \mathrm{MW}$. The ED problem is solved using the enhanced genetic algorithm (EGA), differential evolutionary algorithm (DEA) and AFSOA.

Table 1 presents the scheduled power outputs and the objective function values for the 6 bus - 3 generator system by varying the power demands. When $\mathrm{P}_{\mathrm{D}}$ is $300 \mathrm{MW}$, the obtained total operating cost using EGA, DEA and AFSO algorithms is $3353.23 \$ / \mathrm{hr}$, $3352.96 \$ / \mathrm{hr}$ and $3351.84 \$ / \mathrm{hr}$, respectively, and also the total transmission losses obtained are $2.14 \mathrm{MW}, 1.95 \mathrm{MW}$ and $1.84 \mathrm{MW}$, respectively. From this, it can be observed that the obtained transmission losses and the objective function values are optimum using the AFSOA. This can also be observed by varying the $\mathrm{P}_{\mathrm{D}}$ to $850 \mathrm{MW}$ and $1150 \mathrm{MW}$.

Table 1: Scheduled Power Outputs and Objective Function Values for 6 Bus System

\begin{tabular}{|c|c|c|c|c|c|c|c|}
\hline \multirow[b]{2}{*}{$\mathrm{P}_{\mathrm{D}}(\mathrm{MW})$} & \multirow[b]{2}{*}{ Solution Approach } & \multicolumn{3}{|c|}{ Scheduled Power Generation } & \multirow{2}{*}{$\begin{array}{l}\text { Power Loss } \\
\text { (MW) }\end{array}$} & \multirow{2}{*}{$\begin{array}{l}\text { Total Generation } \\
\text { (MW) }\end{array}$} & \multirow{2}{*}{$\begin{array}{l}\text { Operating Cos } \\
(\$ / \mathrm{hr})\end{array}$} \\
\hline & & $\mathrm{P}_{\mathrm{G} 1}(\mathrm{MW})$ & $\mathrm{P}_{\mathrm{G} 2}(\mathrm{MW})$ & $\mathrm{P}_{\mathrm{G} 3}(\mathrm{MW})$ & & & \\
\hline \multirow{4}{*}{300} & EGA & 150 & 102.14 & 50 & 2.14 & 302.14 & 3353.23 \\
\hline & DEA & 150 & 101.95 & 50 & 1.95 & 301.95 & 3352.96 \\
\hline & AFSOA & 150 & 101.84 & 50 & 1.84 & 301.84 & 3351.84 \\
\hline & EGA & 429.89 & 303.75 & 132.53 & 16.17 & 866.17 & 8303.13 \\
\hline \multirow[t]{3}{*}{850} & DEA & 429.51 & 302.46 & 133.42 & 15.29 & 865.39 & 8302.42 \\
\hline & AFSOA & 393.04 & 344.50 & 121.48 & 15.05 & 865.02 & 8288.86 \\
\hline & EGA & 595.20 & 400 & 184.17 & 29.37 & 1179.37 & 11261.96 \\
\hline \multirow[t]{2}{*}{1150} & DEA & 594.82 & 400 & 184.25 & 29.07 & 1179.07 & 11260.75 \\
\hline & AFSOA & 599.86 & 400 & 178.69 & 28.55 & 1178.55 & 11258.24 \\
\hline
\end{tabular}




\subsection{Simulation results on IEEE 30 bus - 6 generator system}

In this case, the required data of IEEE 30 bus - 6 generator system is taken from [30] and the B-coefficients are calculated using the procedure described in [31]. The obtained B-coefficients are given by,

$\mathrm{B}=\left[\begin{array}{cccccc}0.0001 & 0.0 & 0.0 & 0.0 & 0.0002 & 0.0001 \\ 0.0 & 0.0004 & 0.0002 & 0.0003 & 0.0005 & 0.0004 \\ 0.0 & 0.0002 & 0.0008 & 0.0007 & 0.0005 & 0.0006 \\ 0.0 & 0.0003 & 0.0007 & 0.0008 & 0.0007 & 0.0007 \\ 0.0002 & 0.0005 & 0.0005 & 0.0007 & 0.0018 & 0.0008 \\ 0.0001 & 0.0004 & 0.0006 & 0.0007 & 0.0008 & 0.0010\end{array}\right]$
In this case, two load demands $220 \mathrm{MW}$ and $283.4 \mathrm{MW}$ are considered, and they are solved using EGA, DEA and AFSO algorithms. Table 2 presents the scheduled power outputs and objective function values for IEEE 30 bus system.

When the load demand of $220 \mathrm{MW}$ is considered, then the obtained optimum operating cost using EGA, DEA and AFSO algorithms are $590.65 \$ / \mathrm{hr}, 589.91 \$ / \mathrm{hr}$ and $587.53 \$ / \mathrm{hr}$, respectively, and the optimum system losses are 7.48MW, 7.42MW and $6.70 \mathrm{MW}$, respectively. From these simulation results, it can be observed that the AFSO algorithm has presented the better results compared to EGA and DE algorithms. This can also be seen from the power demand of 283.4MWs.

Table 2: Scheduled Power Outputs and Objective Function Values for IEEE 30 Bus System

\begin{tabular}{|c|c|c|c|c|c|c|}
\hline \multirow{2}{*}{$\begin{array}{l}\text { Scheduled Generation and Objective } \\
\text { function value }\end{array}$} & \multicolumn{3}{|c|}{ Power Demand $\left(\mathrm{P}_{\mathrm{D}}\right)=220 \mathrm{MW}$} & \multicolumn{3}{|c|}{ Power Demand $\left(\mathrm{P}_{\mathrm{D}}\right)=283.4 \mathrm{MW}$} \\
\hline & EGA & DEA & AFSOA & EGA & DEA & AFSOA \\
\hline $\mathrm{P}_{\mathrm{G} 1}(\mathrm{MW})$ & 138.02 & 137.49 & 137.26 & 189.55 & 189.31 & 189.24 \\
\hline $\mathrm{P}_{\mathrm{G} 2}(\mathrm{MW})$ & 36.17 & 36.68 & 36.19 & 47.43 & 47.55 & 47.31 \\
\hline $\mathrm{P}_{\mathrm{G} 3}(\mathrm{MW})$ & 15.00 & 15.00 & 15.00 & 15.00 & 15.00 & 15.00 \\
\hline $\mathrm{P}_{\mathrm{G} 4}(\mathrm{MW})$ & 16.29 & 16.25 & 16.20 & 19.56 & 19.41 & 19.40 \\
\hline $\mathrm{P}_{\mathrm{G} 5}(\mathrm{MW})$ & 10.00 & 10.00 & 10.00 & 10.11 & 10.09 & 10.00 \\
\hline $\mathrm{P}_{\mathrm{G} 6}(\mathrm{MW})$ & 12.00 & 12.00 & 12.00 & 12.00 & 12.00 & 12.00 \\
\hline Power Loss (MW) & 7.48 & 7.42 & 6.70 & 10.25 & 9.96 & 9.55 \\
\hline Total Generation (MW) & 227.48 & 227.42 & 226.70 & 293.65 & 293.36 & 292.95 \\
\hline Operating Cost $(\$ / \mathrm{hr})$ & 590.65 & 589.91 & 587.53 & 806.14 & 803.44 & 801.16 \\
\hline
\end{tabular}

\subsection{Simulation results on 20 generating units system}

The data required for performing the ED problem on 20 generating units is taken from [32]. Here, the ED is performed by considering 2 power demands, i.e., $\mathrm{P}_{\mathrm{D}}$ is $1200 \mathrm{MW}$ and $3600 \mathrm{MW}$. The ED problem is solved using the enhanced genetic algorithm (EGA), differential evolutionary algorithm (DEA) and AFSO algorithms.

Table 3 presents the scheduled power outputs and the objective function values for the 20 generating unit system by varying the power demands. When $P_{D}$ is $1200 \mathrm{MW}$, the obtained total operating cost using EGA, DEA and AFSO algorithms is $36134.6 \$ / \mathrm{hr}$, $36059.3 \$ / \mathrm{hr}$ and $35971.8 \$ / \mathrm{hr}$, respectively, and also the total transmission losses obtained are 29.29MW, 28.04MW and 22.30MW, respectively. From this, it can be observed that the obtained transmission losses and the objective function values are optimum using the AFSO algorithm. This can also be observed by varying the $P_{D}$ to $3600 \mathrm{MW}$.

Table 3: Scheduled Power Outputs and Objective Function Values for 20 Generating Unit System

\begin{tabular}{|c|c|c|c|c|c|c|}
\hline \multirow{2}{*}{$\begin{array}{l}\text { Scheduled Generation and Objective func- } \\
\text { tion value }\end{array}$} & \multicolumn{3}{|c|}{ Power Demand $\left(P_{D}\right)=1200 \mathrm{MW}$} & \multicolumn{3}{|c|}{ Power Demand $\left(\mathrm{P}_{\mathrm{D}}\right)=3600 \mathrm{MW}$} \\
\hline & EGA & DEA & AFSOA & EGA & DEA & AFSOA \\
\hline $\mathrm{P}_{\mathrm{G} 1}(\mathrm{MW})$ & 150 & 150 & 150 & 600 & 600 & 600 \\
\hline $\mathrm{P}_{\mathrm{G} 2}(\mathrm{MW})$ & 50 & 50 & 50 & 200 & 200 & 200 \\
\hline $\mathrm{P}_{\mathrm{G} 3}(\mathrm{MW})$ & 50 & 50 & 50 & 161.45 & 164.45 & 166.20 \\
\hline $\mathrm{P}_{\mathrm{G} 4}(\mathrm{MW})$ & 50 & 50 & 50 & 200 & 200 & 100 \\
\hline $\mathrm{P}_{\mathrm{G} 5}(\mathrm{MW})$ & 50 & 50 & 50 & 160 & 160 & 160 \\
\hline $\mathrm{P}_{\mathrm{G} 6}(\mathrm{MW})$ & 20 & 20 & 20 & 100 & 100 & 100 \\
\hline $\mathrm{P}_{\mathrm{G} 7}(\mathrm{MW})$ & 86.96 & 84.90 & 74.11 & 125 & 125 & 125 \\
\hline $\mathrm{P}_{\mathrm{G} 8}(\mathrm{MW})$ & 50 & 50 & 50 & 150 & 150 & 150 \\
\hline $\mathrm{P}_{\mathrm{G} 9}(\mathrm{MW})$ & 50 & 50 & 50 & 200 & 200 & 200 \\
\hline $\mathrm{P}_{\mathrm{G} 10}(\mathrm{MW})$ & 30 & 30 & 30 & 150 & 150 & 150 \\
\hline $\mathrm{P}_{\mathrm{G} 11}(\mathrm{MW})$ & 152.24 & 153.29 & 155.62 & 300 & 300 & 300 \\
\hline $\mathrm{P}_{\mathrm{G} 12}(\mathrm{MW})$ & 217.64 & 217.64 & 227.42 & 500 & 500 & 500 \\
\hline $\mathrm{P}_{\mathrm{G} 13}(\mathrm{MW})$ & 66.45 & 66.45 & 61.29 & 160 & 160 & 160 \\
\hline $\mathrm{P}_{\mathrm{G} 14}(\mathrm{MW})$ & 20 & 20 & 20 & 130 & 130 & 130 \\
\hline $\mathrm{P}_{\mathrm{G} 15}(\mathrm{MW})$ & 25 & 25 & 25 & 185 & 185 & 185 \\
\hline $\mathrm{P}_{\mathrm{G} 16}(\mathrm{MW})$ & 31.00 & 30.76 & 27.89 & 65.29 & 57.29 & 49.07 \\
\hline $\mathrm{P}_{\mathrm{G} 17}(\mathrm{MW})$ & 30 & 30 & 30 & 85 & 85 & 85 \\
\hline $\mathrm{P}_{\mathrm{G} 18}(\mathrm{MW})$ & 30 & 30 & 30 & 120 & 120 & 120 \\
\hline $\mathrm{P}_{\mathrm{G} 19}(\mathrm{MW})$ & 40 & 40 & 40 & 120 & 120 & 120 \\
\hline $\mathrm{P}_{\mathrm{G} 20}(\mathrm{MW})$ & 30 & 30 & 30 & 100 & 100 & 100 \\
\hline Power Loss (MW) & 29.29 & 28.04 & 22.30 & 211.72 & 206.4 & 200.28 \\
\hline Total Generation (MW) & 1229.30 & 1228.05 & 1222.3 & 3811.7 & 3811.7 & 3800.3 \\
\hline Operating Cost $(\$ / \mathrm{hr})$ & 36134.6 & 36059.3 & 35971.8 & 86612.2 & 86580.9 & 86430.8 \\
\hline
\end{tabular}




\section{Conclusion}

In this paper, a practical economic dispatch (ED) problem is solved considering the valve point loading (VPL) and prohibited operating zones (POZs) effects. From the literature, it can be observed that it is impossible to handle all the types of nonconvexities that arise in practical power systems using the conventional optimization techniques. Hence, the Artificial Fish Swarm Optimization Algorithm (AFSOA) is used in this paper to solve the proposed ED problem. All the constraints, i.e., loss constraint, generators ramp rate constraints and network constraints are considered in this paper. The simulation results are performed on standard 3, 6 and 20 generating unit systems, and the obtained results show the effectiveness of the proposed approach.

\section{Acknowledgment}

This research work is based on the support of "Woosong University Academic Research Funding-2018".

\section{References}

[1] M.M. Delshad, N. AbdRahim, Solving non-convex economic dispatch problem via backtracking search algorithm, Energy, vol. 77 (2014), pp. 372-381. https://doi.org/10.1016/j.energy.2014.09.009.

[2] G. Binetti, D. Naso, B. Turchiano, A. Davoudi, F.L. Lewis, Consensus-based Approach for the Economic Dispatch Problem, IFAC Proceedings Volumes, vol. 47, no. 3, (2014), pp. 3140-3145.

[3] W.T. Elsayed, Y.G. Hegazy, F.M. Bendary, M.S. El-Bages, A review on accuracy issues related to solving the non-convex economic dispatch problem, Electric Power Systems Research, vol. 141, (2016), pp. 325-332. https://doi.org/10.1016/j.epsr.2016.08.002.

[4] M. Basu, A. Chowdhury, Cuckoo search algorithm for economic dispatch, Energy, vol. 60, (2013), pp. 99-108. https://doi.org/10.1016/j.energy.2013.07.011.

[5] N. Ghorbani, E. Babaei, Exchange market algorithm for economic load dispatch, International Journal of Electrical Power \& Energy Systems, vol. 75, (2016), pp. 19-27. https://doi.org/10.1016/j.ijepes.2015.08.013.

[6] V.S. Aragón, S.C. Esquivel, C.A.C. Coello, An immune algorithm with power redistribution for solving economic dispatch problems, Information Sciences, vol. 295, (2015), pp. 609-632. https://doi.org/10.1016/j.ins.2014.10.026.

[7] Y.A. Gherbi, H. Bouzeboudja, F.Z.Gherbi, The combined economic environmental dispatch using new hybrid metaheuristic, Energy, vol. 115, no. 1, (2016), pp. 468-477. https://doi.org/10.1016/i.energy.2016.08.079

[8] M. Basu, Improved differential evolution for economic dispatch, International Journal of Electrical Power \& Energy Systems, vol. 63, (2014), pp. 855-861. https://doi.org/10.1016/j.ijepes.2014.07.003.

[9] K. Mason, J. Duggan, E. Howley, Multi-objective dynamic economic emission dispatch using particle swarm optimisation variants, Neurocomputing, vol. 270, (2017), pp. 188-197. https://doi.org/10.1016/j.neucom.2017.03.086.

[10] W.T. Elsayed, Y.G. Hegazy, F.M. Bendary, M.S. El-bages, Modified social spider algorithm for solving the economic dispatch problem, Engineering Science and Technology, an International Journal, vol. 19 , no. 4, (2016), pp. 1672-1681.

[11] B.R. Adarsh, T. Raghunathan, T. Jayabarathi, X.S. Yang, Economic dispatch using chaotic bat algorithm, Energy, vol. 96, (2016), pp. 666-675. https://doi.org/10.1016/j.energy.2015.12.096.

[12] T. Jayabarathi, T. Raghunathan, B.R. Adarsh, P.N. Suganthan, Economic dispatch using hybrid grey wolf optimizer, Energy, vol. 111, (2016), pp. 630-641. https://doi.org/10.1016/j.energy.2016.05.105.

[13] L. Han, C.E. Romero, Z. Yao, Economic dispatch optimization algorithm based on particle diffusion, Energy Conversion and Management, vol. 105, (2015), pp. 1251-1260. https://doi.org/10.1016/j.enconman.2015.08.071.

[14] S.D. Beigvand, H. Abdi, M.L. Scala, A general model for energy hub economic dispatch, Applied Energy, vol. 190, (2017), pp. 1090-1111. https://doi.org/10.1016/j.apenergy.2016.12.126.
[15] B. Lokeshgupta, S. Sivasubramani, Multi-objective dynamic economic and emission dispatch with demand side management, International Journal of Electrical Power \& Energy Systems, vol. 97, (2018), pp. 334-343. https://doi.org/10.1016/j.ijepes.2017.11.020.

[16] G. Xiong, D. Shi, Orthogonal learning competitive swarm optimizer for economic dispatch problems, Applied Soft Computing, vol. 66, (2018), pp. 134-148. https://doi.org/10.1016/j.asoc.2018.02.019.

[17] F.P. Mahdi, P. Vasant, V. Kallimani, J. Watada, P.Y.S. Fai, M.A. Al-Wadud, A holistic review on optimization strategies for combined economic emission dispatch problem, Renewable and Sustainable Energy Reviews, vol. 81, no. 2, (2018), pp. 3006-3020. https://doi.org/10.1016/j.rser.2017.06.111.

[18] M. Ramzanpour, H. Abdi, Economic Load Dispatch with Considering the Valve-Point Effects and Ramp Rate Limits of Generators Using Evolutionary Algorithms, Journal of Advances in Computer Research, vol. 5, no. 3, (2014), pp. 69-84.

[19] G. Chandrakala, V. Ramakrishna, J.B. Shaik, Solving economic dispatch with valve point loading effects by using optimization techniques, International Journal of Engineering Science Invention, vol. 3, no. 9, (2014), pp. 1-11.

[20] G.K. Babu, R.K. Samala, Network and Generator Constrained Economic Dispatch Using Real and Binary Coded Genetic Algorithms, Journal of Engineering Research and Applications, vol. 3, no. 5, (2013), pp. 1185-1192.

[21] S. Vijayaraj, R.K. Santhi, Economic Dispatch with Prohibited Zones Using Improved Bat Algorithm, International Journal of Advanced Research in Electrical, Electronics and Instrumentation Engineering, vol. 5, no. 11, (2016), pp. 8301-8308.

[22] P.K. Hota, N.C. Sahu, Non-Convex Economic Dispatch with Prohibited Operating Zones through Gravitational Search Algorithm, International Journal of Electrical and Computer Engineering, vol. 5, no. 6, (2015), pp. 1234-1244.

[23] X.Y. Luan, Z.P. Li, T.Z. Liu, A novel attribute reduction algorithm based on rough set and improved artificial fish swarm algorithm, Neurocomputing, vol. 174, no. A, (2016), pp. 522-529.

[24] N. Fang, J. Zhou, R. Zhang, Y. Liu, Y. Zhang, A hybrid of real coded genetic algorithm and artificial fish swarm algorithm for short-term optimal hydrothermal scheduling, Electrical Power and Energy Systems, vol. 62, (2014), pp. 617-629. https://doi.org/10.1016/j.ijepes.2014.05.017.

[25] K.P. Kumara, B. Saravanana, K.S. Swarup, Optimization of Renewable Energy Sources in a Microgrid Using Artificial Fish Swarm Algorithm, Energy Procedia, vol. 90, (2016), pp. 107-113. https://doi.org/10.1016/j.egypro.2016.11.175.

[26] Q. He, X. Hub, H. Ren, H. Zhang, A novel artificial fish swarm algorithm for solving large-scale reliability-redundancy application problem, ISA Transactions, vol. 59, (2015), pp. 105-113. https://doi.org/10.1016/j.isatra.2015.09.015.

[27] Y. Wang, Artificial Fish Swarm Algorithm based Optimization of Load Dispatch Problem for GTCC Units, International Journal of Engineering Research \& Technology, vol. 5, no. 1, (2016), pp. 340344.

[28] Y. Tian, C. Lu, Z. Wang, L. Tao, Artificial Fish Swarm AlgorithmBased Particle Filter for Li-Ion Battery Life Prediction, Hindawi Publishing Corporation Mathematical Problems in Engineering, vol. 204, (2014), pp. 1-10.

[29] M. Ribbens-Pavella, T. Van Cutsem, P. Rousseaux, "On-Line Stability and Dynamic Security Assessment of Electric Power Systems", Proc. Of the IFAC Symposium on Planning and Operation of Electric Energy Systems, Rio de Janeiro, Brazil, July 22- 25, 1985. https://doi.org/10.1016/S1474-6670(17)60411-7.

[30] P. Rousseaux, Th. Van Cutsem, T.E. Dy Liacco, "Whither Dynamic State Estimation?", Electrical Power \& Energy Systems, Vol. 12, No. 2, Apr. 1990, pp. 104-116. https://doi.org/10.1016/01420615(90)90006-W.

[31] A. Garcia, A. Monticelli, and P. Abreu, "Fast Decoupled State Estimation and Bad Data Processing," IEEE Transaction Power App. and Syst., Vol. PAS-98, pp. 1645-1652, Sept. 1979. https://doi.org/10.1109/TPAS.1979.319482.

[32] T.E. Dy Liacco, "An Overview of Power System Control Centers", Energy Control Center Design, IEEE Tutorial Course, TU00109PWR, 1977. 